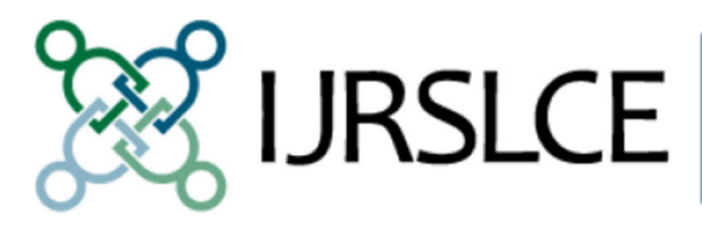

International Journal

for Research on

Service-Learning \&

Community Engagement

Article 3

2017

\title{
Out of the Armchair: About Community Impact
}

\section{Alan H. Bloomgarden}

This article was originally published at:

https://journals.sfu.ca/iarslce/index.php/journal/article/view/307/198

Recommended Citation

Bloomgarden, A. H. (2017). Out of the armchair: About community impact. International Journal of Research on Service-Learning and Community Engagement, 5(1), 21-23. 


\title{
Out of the Armchair: About Community Impact
}

\author{
Alan H. Bloomgarden \\ Section Co-Editor, Community Partnerships
}

Those of us who consider ourselves practitioner-scholars in the service-learning field are mostly preoccupied with facilitating learning and inquiry through community-engaged practice. It is hardly surprising, then, that our work to develop and steward collaborations with communities and organizations leads us to ask, foremost and at times exclusively, whether we have advanced knowledge and capacities among our students, our faculty, and staff colleagues. We may also ask whether community-engaged practices have enhanced the programs our institutions treasure. Like me, I'm sure many of us, either to explain or excuse this inward focus, frequently remind community partners that we who do this work on college campuses are typically marginal and under-resourced in our respective contexts, and that faculty colleagues who undertake this work are often unrewarded or at least under-valued for their efforts. All of this, of course, is true, speaking to our preoccupation with these results, in part, as a matter of addressing our institutional contexts.

In these contexts, where other priorities carry more capital, status, and reward, it may be unsurprising that the efforts and resources we do devote to demonstrating effects and impacts focus almost entirely upon outcomes most valued and understood by our colleagues - student learning and knowledge production. This is still deeply troubling. At best, we might pay modest attention to goals that are associated with and complementary to these internal, educational objectives. Such goals might include maintaining sustainable access to community partnerships that enable learning and research outcomes; accessing forms of community-owned capital like data resources, historical and contextual knowledge, local leadership, and development networks; and emerging opportunities for learning and research. However, by and large, and despite much perennial hand-wringing, our field has witnessed little systematic and scholarly treatment of and progress around questions and challenges we face in our collective attempt to design and implement lasting, meaningful community impacts through community engagement partnerships with higher education institutions. Inquiry into and scholarship about where, how, when, and why campus-community engagement does or does not contribute to or facilitate community-valued development outcomes that are systemic and sustainable is woefully thin. At best, and too often, reporting and analysis about whether and how campus-driven community engagement becomes collaborative work apply a community impact lens ex post facto rather than as a design feature baked into the principles and practices of partnership. We are, in effect, preoccupied with only a segment of our complex and interdependent ecosystem, and we treat this fundamental matter of equity, inclusion, and voice as an afterthought — to our detriment, practically and morally, in our work.

There is much to be said and considered about why it might be true that our community of community-engaged scholars has rested extensively and, I would argue, too comfortably in our armchairs when it comes to critiquing the designs, priorities, and practices underpinning our work in and with communities. Where those concerns go beyond questions of "How was it for us?" we remain shortsighted for a great many reasons. However, I write this at a particular moment, in this particular venue, in which I prefer strongly to take a forward-looking stance of optimism and encouragement rather than reflect upon a shortcoming already evidenced by the dearth of material in this section of the IJRSLCE. We are entering the annual season of holiday giving at the close of a year in which generosity and kindness of spirit on the national stage have been hard to find. Rather than suggest we do not care deeply about questions of community impact and equitable partnership, I hold out optimism that we have just not attended to constructing, studying, and theorizing this subfield. So I am making the choice here and now to focus on my "wish list" as a practitioner-scholar of community engagement, rather than upon the angst I and many I know sometimes feel about questions like, "What are we doing?", "Who are we benefitting, really?", 
and "Why?"- not least of whom include the inspiring Nadinne Cruz in her powerful, stunning keynote at the 2016 IARSLCE conference in New Orleans.

Thus, I raise some questions and challenges I believe our field would appreciate having addressed in the coming year by researchers through systematic inquiry, reflection and case study, and experiencebased theory building. There are not only questions and challenges that we need to know more about to improve our practice, but ones that must be reflected upon and considered as a means of moving our work from its understandable yet unfortunate and counter-productive inward preoccupation. We need this inquiry to focus ourselves, our students, and our institutions squarely upon wider societal concerns that have not only great urgency and significance on their own, but also pervasive implications for our capacity to continue and advance community-engaged practices and partnerships. These include questions and challenges of: sustainability; inclusion, democratic practice, and social justice; mutuality and reciprocity; ethics; and alignment and collaboration in design and practice. There is much more to say about each of these summary phrases to capture the depth and breadth each question and challenge poses to our philosophies of engagement, our organizational and collaborative practices, and our approaches to teaching and research. Overall, they might best be seen as subcategories of focus for lines of scholarly inquiry into basic questions: Are things changed, for better or for worse, in the community, consequent or connected to our engagement and interaction? How, and why or why not? Internally oriented and often prone to the precarious, we find it difficult to answer these questions critically. Yet, just as critically, what are we doing if we cannot even try? More positively, I am confident that we, our students, and our institutions will find community-engaged practices more meaningful and impactful through such inquiry.

This is a call to scholars in our field to address these questions and challenges directly in the study and analysis of community engagement partnerships for service-learning, community-based research, and campus-community collaborations. Here are some fantasy titles for articles that best capture the spirit and intent embedded in this call:

- "Moving the Needle: How a School District Aligned Efforts among 23 Metropolitan Area Community Partners and Seven Higher Education Institutions to Advance 100\% High School Graduation Rates"

- "The Heard Voices: Eliciting and Placing Resident and Leader Perspectives on Community Development at the Core of University-Community Collaboration in Somewhereville"

- "From Lived Experience to Participatory Inquiry: Facilitating Sustained Community-Driven Research about Socioeconomic Mobility among Wage Workers"

- “We Went Down to the Crossroads': Theorizing Alignment between Nonprofit Organizational Priorities and Practices and Campus-Paid and Credit-Bearing Student Placements"

- "From Traffic Management to Collective Impact: How Coalition Leaders Changed the Dynamics of Power and Practice in Campus-Community Discourse"

- "Outpacing the Revolving Door: Building Stable Collaborations in Conditions of Constant Transition among Campus and Community Partners"

- "The Responsive University: Adapting Infrastructure and Resource Allocation to Evolving Community Development and Learning Opportunities" 
- “Alibis, Allies, and Accomplices: Enlisting Community Member Perspectives to Frame Challenges of Entry and Post-Experience Reflection for Undergraduates in a Service-Learning Course"

- "From Transaction to Transformation: An Inquiry into Conditions that Support and Frustrate Reciprocity and Inclusive Practices in College-Community Collaboration"

- "Community Voice in Project and Organizational Design: (Re)Constructing the Office of Community Engagement from the Ground Up"

IJRSLCE and the field itself will be stronger if we can contribute to both analysis and guidance that advances the voices, needs, knowledge, and priorities that emerge in what are, at best, poorly understood partnership dynamics. At worst, we might look upon this problem of unit-level analysis of campuscommunity partnerships as systematically underrepresented and structurally disenfranchised by our systems of reward, epistemology, and inquiry. Rather than allow the nature and consequences of campuscommunity partnership to languish as a poorly understood and largely overlooked line of scholarly inquiry and critique, let's give these topics the value and attention they deserve as essential elements to our community engagement ecosystem and collaborative economy.

\section{Author Note:}

Alan Bloomgarden is Director of Community Engagement at Mount Holyoke College 